\title{
Form and Style in Two of Percy Grainger's Early Works for Military Band
}

\section{John Dixon}

College of the Arts

Faculty Mentor: Rich Pellegrin, Department of Music

\begin{abstract}
Percy Grainger often crosses genres in his works and explores a variety of instrumentations and stylistic choices. Grainger's popularity arose from his arrangements of traditional folk songs that he recorded using a phonograph; however, even his original works have a clear folk influence, despite using more modern harmony. This paper examines Grainger's compositional style in two original works for the military band setting, namely Children's March: Over the Hills and Far Away and Colonial Song. Each work is analyzed through the lens of harmony, melody, form, texture, and rhythm to determine key aspects of the composition. The article then compares the two analyses to identify recurring aspects of Grainger's compositional style. In both Children's March and Colonial Song, Grainger establishes simple tertian harmony as the standard, using descending chromaticism and increased note density to provide additional tension. Both pieces have diatonic melodies and a simple form, as well as a mixture of homophony and polyphony. In addition, Grainger uses rhythmic driving forces and short-long patterns, which are common features of the folk music he recorded. Considering all of these elements, Grainger employs a combination of traditional musical techniques and complex harmony, producing a folk-like style that is unique and easily identified.
\end{abstract}

Keywords: Percy Grainger, style, composition, music theory, military band

\section{Introduction}

Percy Grainger wrote numerous pieces in different genres throughout his career that display his fascination with the styles and properties of folk music. This fascination heavily influenced Grainger's compositions; his most popular pieces are arrangements of folk tunes for larger ensembles, but his original compositions are also inspired by the simple melodies and rhythms of traditional British and Irish folk music (Freeman, 2012). Two original works that exemplify Grainger's style are Children's March and Colonial Song, which contain noticeable similarities despite their superficial differences.

Grainger's instrumental arrangements of folk songs provide a twentieth-century adaptation of more traditional melodies. These arrangements have a distinct sound and style unique to Grainger, but his more popular original works also feature a similar sound, despite not directly 
drawing from folk music (Grainger \& Rogers, 1997, p. 3). It is worth analyzing these original works to determine the elements of composition that give Grainger's music its characteristic folk-like sound.

This paper investigates Children's March and Colonial Song in detail to more clearly define Grainger's compositional style. For each piece, analysis is broken into four primary sections:

1. Harmony - analysis of chords, progressions, and pitch patterns at key moments

2. Form and Melody - examination of general structure and melodic organization

3. Texture - classification of texture based on melody, harmony, and counterpoint

4. Rhythm - discussion of recurring rhythmic ideas and their importance

The analysis reveals a significant number of similarities between the two pieces. In both Children's March and Colonial Song, Grainger seamlessly blends simple folk-like melodies and rhythms with more modern musical ideas to create a unique compositional style.

\section{Children's March: "Over the Hills and Far Away"}

\section{Harmony}

Most of Children's March consists of simple chord progressions, with a few key moments of less traditional harmony. Figure 1 exemplifies this harmonic style, featuring a circle of fifths progression consisting of diatonic triads and seventh chords. A majority of the harmony is similarly simple; however, there are a few moments of particular interest in which Grainger adds more complex dissonances. For example, the progression at measure 323 is as follows: Fm7

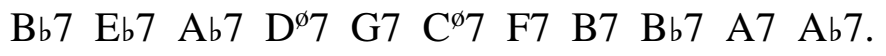

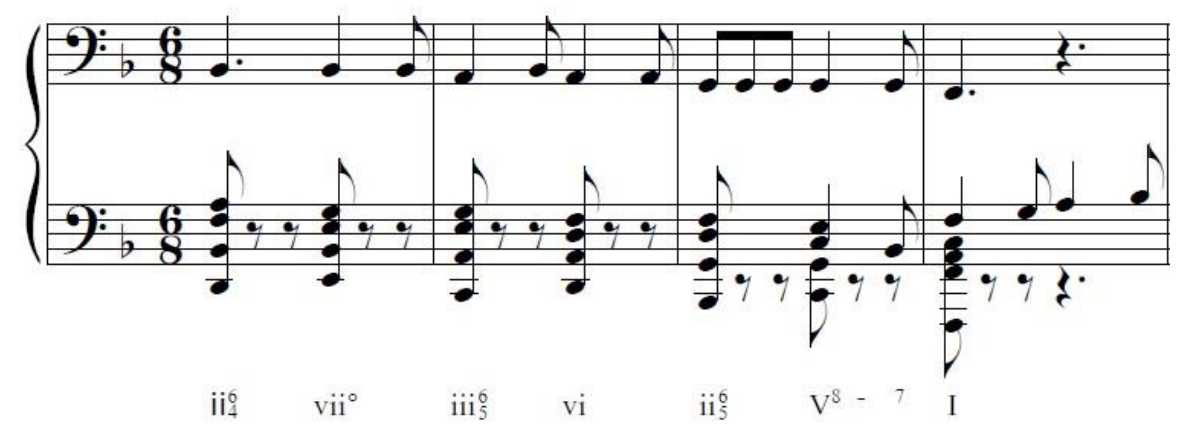

Figure 1. Children's March, mm. 25-28, transcribed from condensed score. Roman numeral analysis in F major (Grainger, 1919). 
This progression consists entirely of seventh chords, which transition from bass motion by descending fifths to descending chromaticism. The use of several dominant seventh chords in a row with descending fifths in the bass allows for an interesting effect; the tritone intervals in these chords form a chain of descending chromaticism. Grainger highlights this motion clearly at measure 323, as shown in Figure 2.

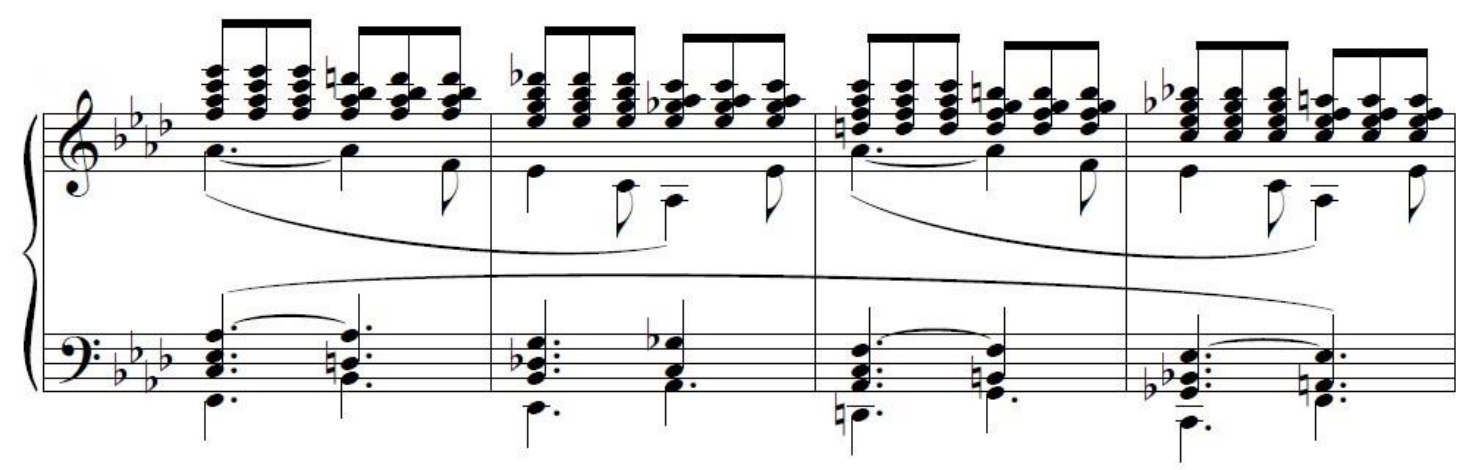

Figure 2. Children's March, mm. 323-324, harmonic reduction (Grainger, 1919).

This descending chromatic sequence creates harmonic tension that slowly and gracefully resolves into a simple ii-V-I progression. Most phrases in the piece end similarly, with simple, authentic cadences, yet the middle of several phrases use less functional chords. In these moments, Grainger prioritizes individual voice leading over functional harmony. For example, measures 12-17 feature the following progression: $\mathrm{B}^{\varnothing} 7 \quad \mathrm{Bb}^{\varnothing} 7 \mathrm{~A}^{\varnothing} 7$ D7 F/A $\mathrm{B}^{\varnothing} 7 / \mathrm{A}$ F/C C7 F. While the last three chords create a simple $\mathrm{I}_{4}^{6}{ }_{4} \mathrm{~V}^{7}-\mathrm{I}$ progression, the earlier chords are less functional. Grainger chooses these chords to allow the oboe and clarinet lines to descend chromatically while still providing a structure and context for the melody. Descending chromaticism is a key feature of this piece's sound, adding tension to otherwise calm and simple progressions. Grainger uses chromatic lines throughout the piece and builds chord progressions around these lines so that they can exist naturally.

Another example of this technique occurs at measure 193, where Grainger writes the progression: Amaj7/B Bb7 Eb7 D7 B $7 / G$. This progression allows for the piano to descend chromatically from $\mathrm{A}$ to $\mathrm{F}$ and the euphonium to descend from $\mathrm{E}$ to $\mathrm{A}$, while also creating the bass line $\mathrm{B}-\mathrm{B} b-\mathrm{E} b-\mathrm{D}$. These chords primarily rely on voice leading and descending chromaticism to build and release tension. Additionally, Grainger uses chromatic motion in the piece's conclusion. During the final bars of Children's March, melodies from the opening theme and A section are blended, but the accompaniment is changed from staccato block chords to descending 
chromatic lines in the clarinets. These lines resemble cluster chords but slowly shift downwards until eventually resolving into more standard chords.

\section{Form and Melody}

Examining the larger structure of Children's March is useful in determining how Grainger plans his compositions. The piece consists of an introduction, alternating A and B sections, and a conclusion that combines the introductory theme with part of the A section (as shown in Figure 3). The introduction is a 16-bar section with a bassoon and saxophone melody and staccato accompaniment. Interestingly, this melody does not return until the piece's conclusion, where it is paired with motives from the A section. After a 4-bar transition, the A section begins, consisting of three blocks of binary form. Each block is 32 bars, with an 8-bar $a$ and $b$ phrase repeated twice. Each time this section is repeated, the melody grows louder and the accompaniment becomes more complex. Immediately after the third A block, the B section begins with a key change from $\mathrm{F}$ to $\mathrm{B} b$ (the subdominant of $\mathrm{F}$ ) and a much calmer melody. Within this B section, there are four 16-bar phrases that have the form abac. The $c$ phrase provides a stark contrast to the $b$ phrase, containing many long chains of tension and release as well as descending chromaticism. This final phrase of the B section serves as a small climax of the piece, although the same phrase is repeated once more later in the piece and provides a larger climax.

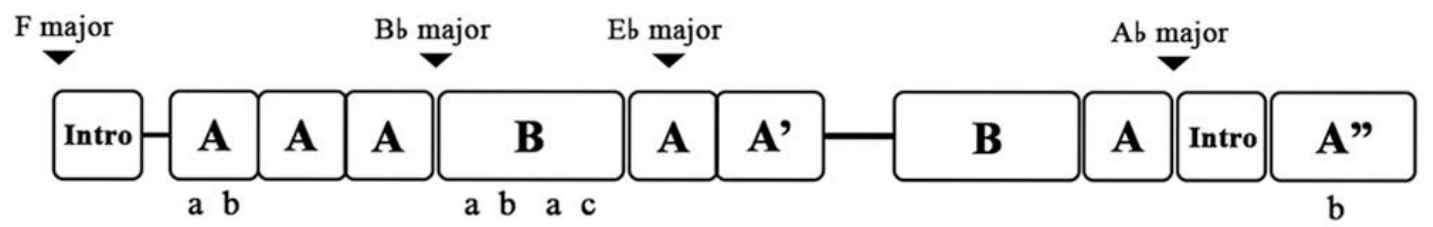

Figure 3. Form analysis of Children's March.

The second A section contains two blocks of 32 bars with the same $a a b b$ form. After the subdominant shift in the previous B section, the listener may expect a return to the original key of $\mathrm{F}$ once the A melody returns. Grainger instead shifts to the key of $\mathrm{Eb}$ (the subdominant of $B b$ ), subverting the expectations of the audience. This A section contains long diatonic runs in the woodwinds, which transition to a much more climactic version of the $\mathrm{B}$ section. The second $\mathrm{B}$ section contains another key change, once again to the subdominant, Ab. It contains the same pattern of phrases from the first section (abac) but with a more diverse accompaniment and aggressive melody. Grainger brings in the entire band at this point and creates large shifts in 
dynamics, preparing for the upcoming climax of the piece. The final 16 bars of this second $\mathrm{B}$ section contain the most tension and chromaticism of the whole piece (see Figure 2), eventually resolving into a simple ii-V-I progression as the tension is released. This leads into a short A section with only one 32-bar block, after which the conclusion of the piece begins. This final section brings back the melody from the introduction as well as motives and ideas from the A section. The piece ends with a $\mathrm{B} b$ drone in the low woodwinds with percussive accompaniment. R. Mark Rogers speculates that Grainger shifts to the key of $\mathrm{B} b$ to allow the bassons to demonstrate their lowest note for a full ten measures (Grainger \& Rogers, 1995).

Figure 4. Children's March, A melody (Grainger, 1919).

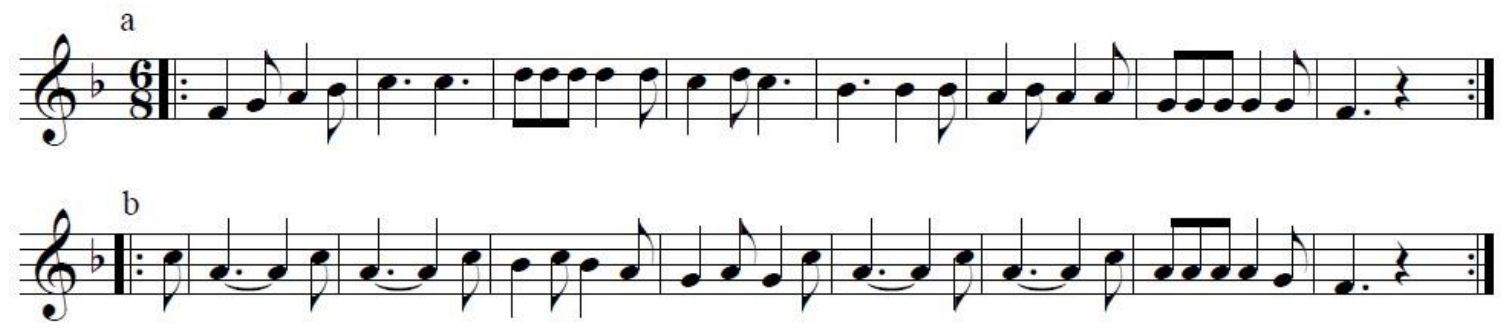

Grainger's use of melody is also notable. Children's March is in compound duple meter

a

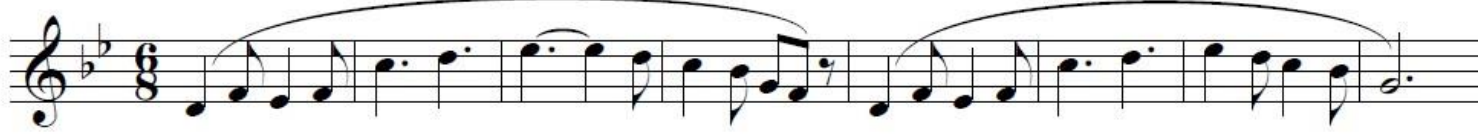

$\mathrm{b}$
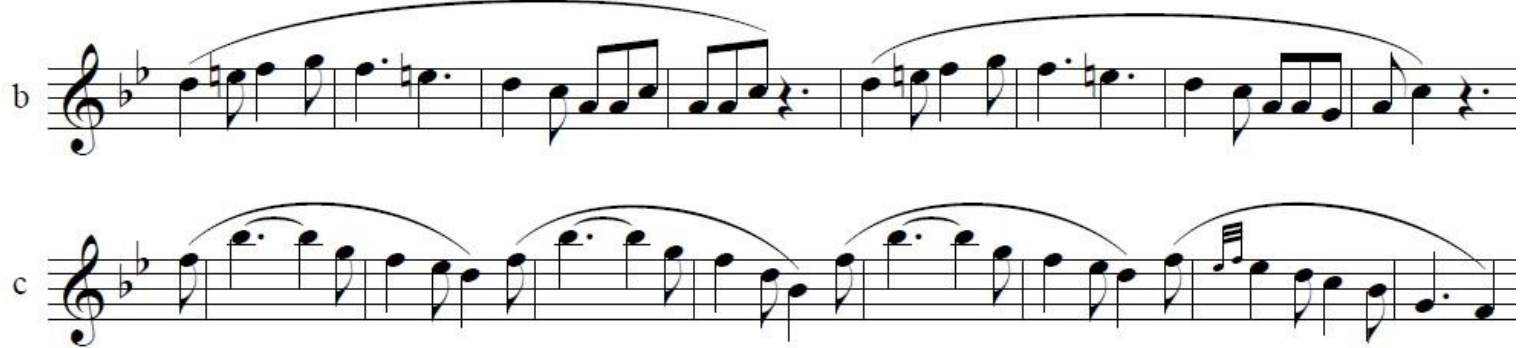

and has a swing feel that is appropriate for the piece's mood. The form of the A melody $(a a b b)$ is repeated several times; this is the most common form for Irish dance tunes (Bakan, 2012), which were a source of inspiration for Grainger. Overall, the melody is simple and mostly stepwise, with only a few short contrapuntal lines accompanying it.

Figure 5. Children's March, beginning of $a, b$, and $c$ phrases of the B melody (Grainger, 1919).

The B melody is much smoother than the A melody and has a more defined melodic contour. Unlike the A melody, each phrase of the B melody has a clear rise, peak, and fall. Grainger only breaks this pattern at the end of the $c$ phrase; the melody leaps to a high $\mathrm{B} b$ and then descends 
with the accompaniment. Once other voices join in with the melody, the lines move in similar motion, often in unisons spanning several octaves.

\section{Texture}

The piece begins with homophony, as a single melody and accompaniment are passed around the ensemble. However, counterpoint begins to develop during the first A section as various lines become independent of the underlying accompaniment. At measure 97, Grainger has the euphoniums and saxophones change notes on the second beat of each measure while the harmony continues to change on the first beat. This added counterpoint shifts the harmonic rhythm of the piece, creating much-needed contrast to the previous set of chord changes. Another notable stylistic choice is Grainger's addition of four vocal parts during the B sections, which are to be sung "by the members of the Band not playing their instruments at this particular moment" (Grainger, 1919). By having part of the ensemble sing along with the music, Grainger emphasizes the folk-like style of the piece; his most popular original works have singable melodies inspired by folk tunes, and Children's March is no exception (Grainger \& Rogers, 1997, p. 3). Grainger continues to use various contrapuntal techniques throughout Children's March, often transitioning between homophony and polyphony.

\section{Rhythm}

Grainger uses a few notable rhythms in Children's March. The "Scotch snap" rhythm consists of a short note on an accented beat followed by a long note on an unaccented beat. While more common in simple meters, a variation of this rhythm can be produced in compound meters by dividing the beat into a 1:2 ratio, as shown in Figure 6 (Temperley \& Temperley, 2011). This 'short-long' rhythm is characteristic of traditional Scottish dance music (Johnson, 2001), which is a close neighbor to the British and Irish folk tunes that inspire many of Grainger's works (Freeman, 2012). The rhythm does not feel out of place in Children's March, but rather adds an air of traditionality to the piece and emphasizes Grainger's folk-inspired style. Additionally, Grainger repeatedly makes use of staccato block chords (see Figure 7), creating a jovial mood without sacrificing harmony or harmonic rhythm. As the piece is a march, there is no change in tempo throughout the song since the continuous beat is meant to serve as a driving 
force. The only section of the piece with an ambiguous tempo is the transition at measure 261, where the high woodwinds play a series of diatonic runs with a drumroll underneath.

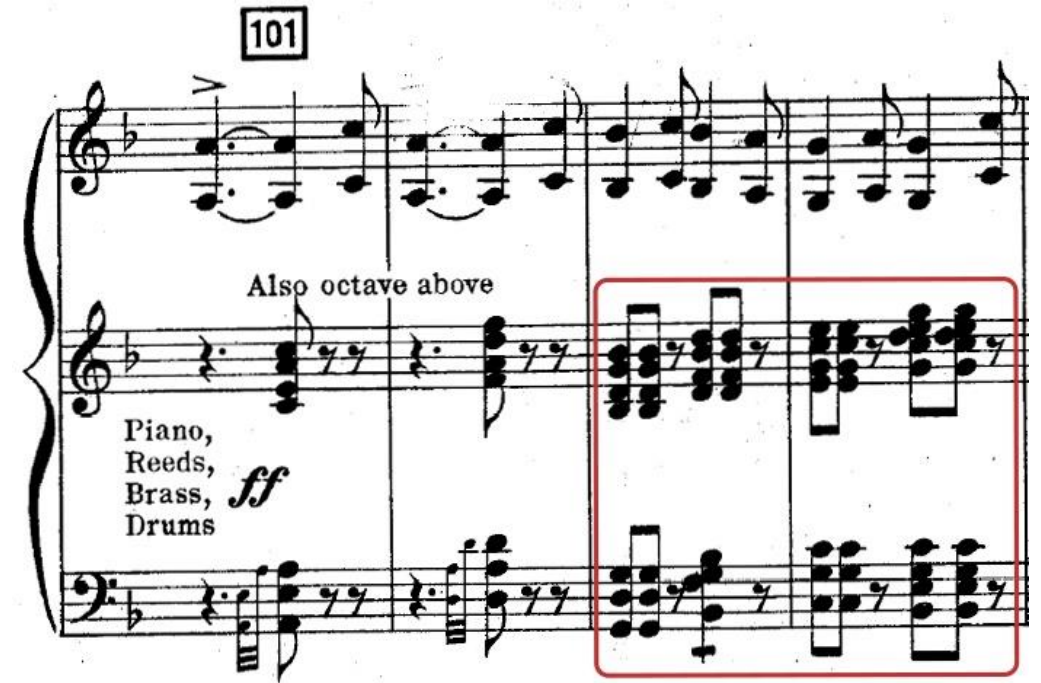

Figure 6. Children's March, mm. 101-104, condensed score. Short-long rhythmic pattern boxed (Grainger, 1919).

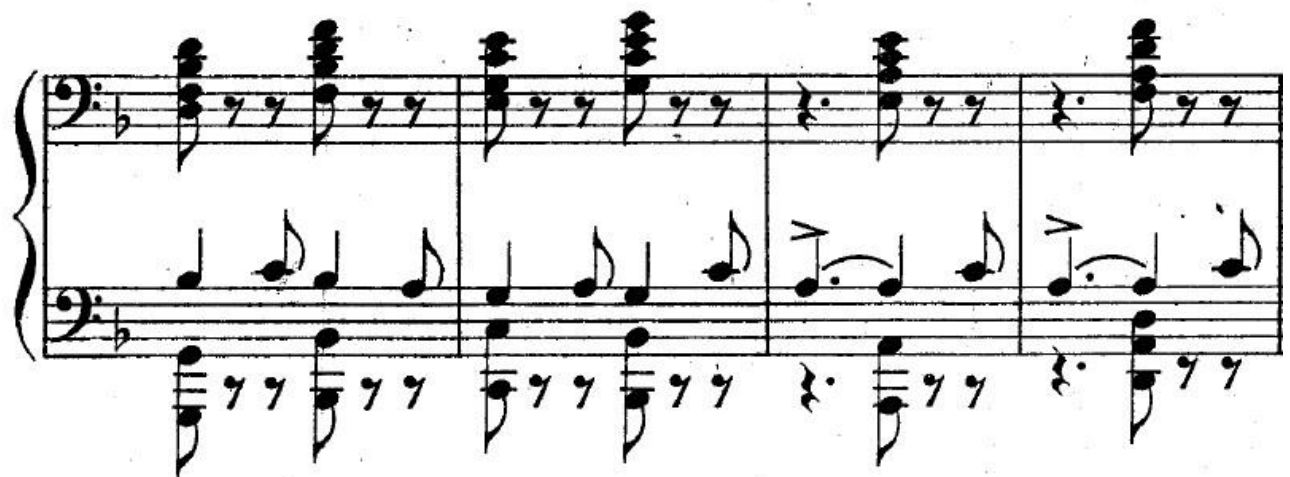

Figure 7. Children's March, mm. 53-56, condensed score. Example of staccato accompaniment (Grainger, 1919).

\section{COLONIAL SONG}

\section{Harmony}

Colonial Song contains a diverse and complex harmony with which Grainger decorates his melodies. A few common chord patterns reoccur, the most notable of which are the ii-I cadence and the secondary dominant $\mathrm{V}^{7} / \mathrm{IV}$ resolving deceptively to $\mathrm{ii}^{7}$ (or $\mathrm{vi}^{7} / \mathrm{IV}$ ). The piece begins with very simple progressions but gradually adds more richness and complexity with each new phrase, as shown in Figure 8. 


\begin{tabular}{c|cccccccc} 
m. 2-3 & I & $\mathrm{V}^{7}$ & $\mathrm{I}$ & $\mathrm{I}^{6}$ & $\mathrm{~V}$ & & & \\
m. 4-5 & $\mathrm{I}$ & $\mathrm{I}^{6}$ & $\mathrm{~V}^{7}$ & $\mathrm{I}$ & $\mathrm{IV}$ & $\mathrm{I}^{6}$ & $\mathrm{~V}^{7} / \mathrm{V}$ & $\mathrm{V}$ \\
$\mathrm{m} .6-8$ & $\mathrm{IV}$ & $\mathrm{ii}^{6}$ & $\mathrm{I}^{6}$ & $\mathrm{~V}_{3}^{4} / \mathrm{V}$ & $\mathrm{I}_{4}^{6}$ & $\mathrm{~V}^{7}$ & & \\
m. 9-11 & $\mathrm{I}$ & vii $^{\circ 6}$ & $\mathrm{~V}_{5}^{6} / \mathrm{IV}$ & $\mathrm{IV}$ & $\mathrm{ii}^{7}$ & $\mathrm{I}_{4}^{6}$ & $\mathrm{~V}^{9}$ & $\mathrm{I}$
\end{tabular}

Figure 8. Colonial Song, Roman numeral analysis of measures 2-11 in Eb major.

In the first five measures of Colonial Song, Grainger restricts the harmony to the I, IV, and V chords and a singular secondary dominant $\left(\mathrm{V}^{7} / \mathrm{V}\right)$. However, the next six measures feature retrograde motion, diminished chords, and less common extensions. Each phrase is more harmonically complex and has a higher concentration of pitches than the previous phrase. These phrases exemplify an interesting harmonic characteristic of Colonial Song, which is Grainger's building of tension through note density. In Figure 8, Grainger builds up to the climactic $\mathrm{V}^{9}$ chord, which resolves gracefully to I.

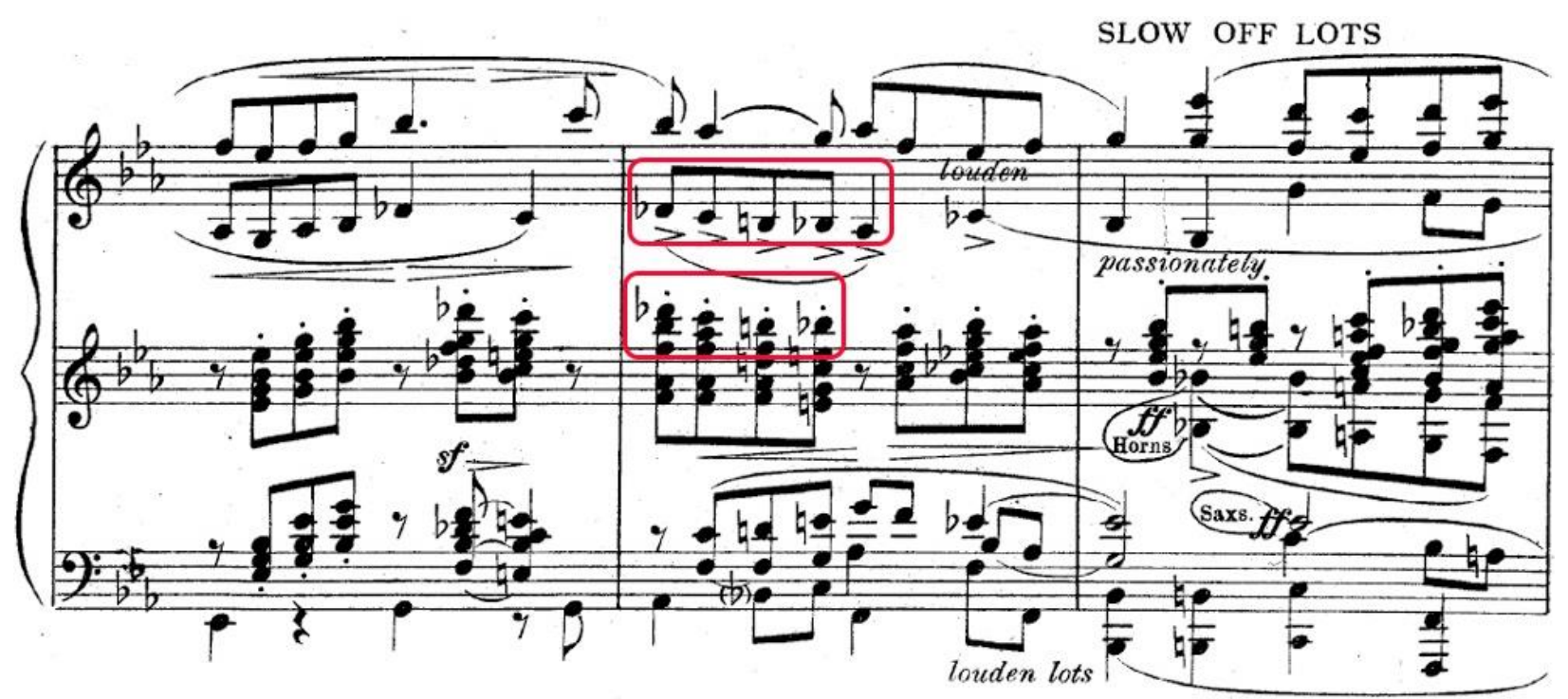

Figure 9. Colonial Song, mm. 33-35, condensed score. Descending chromaticism boxed (Grainger, 1921).

Up until the second B section of Colonial Song, the accompaniment consists mainly of triads and seventh chords, with only a few non-chord tones and extensions. However, this changes at the end of the second B section, as Grainger harmonizes a tense line of descending chromaticism. In Figure 9, Grainger emphasizes the line $\mathrm{D} b-\mathrm{C}-\mathrm{B}-\mathrm{B} b-\mathrm{A}$, building a complex progression of chords that contextualizes this chromaticism. Grainger also increases the density of notes in each chord of this progression, building tension and foreshadowing the upcoming crescendo into the development section of the piece. A very similar progression appears at 
measure 66 (see Figure 10). Grainger emphasizes the line $\mathrm{E} b-\mathrm{D}-\mathrm{D} b-\mathrm{C}-\mathrm{C} b-\mathrm{B} b$ and builds a nonfunctional progression which frames this chromaticism in a way that gives the semblance of functional harmony.

66

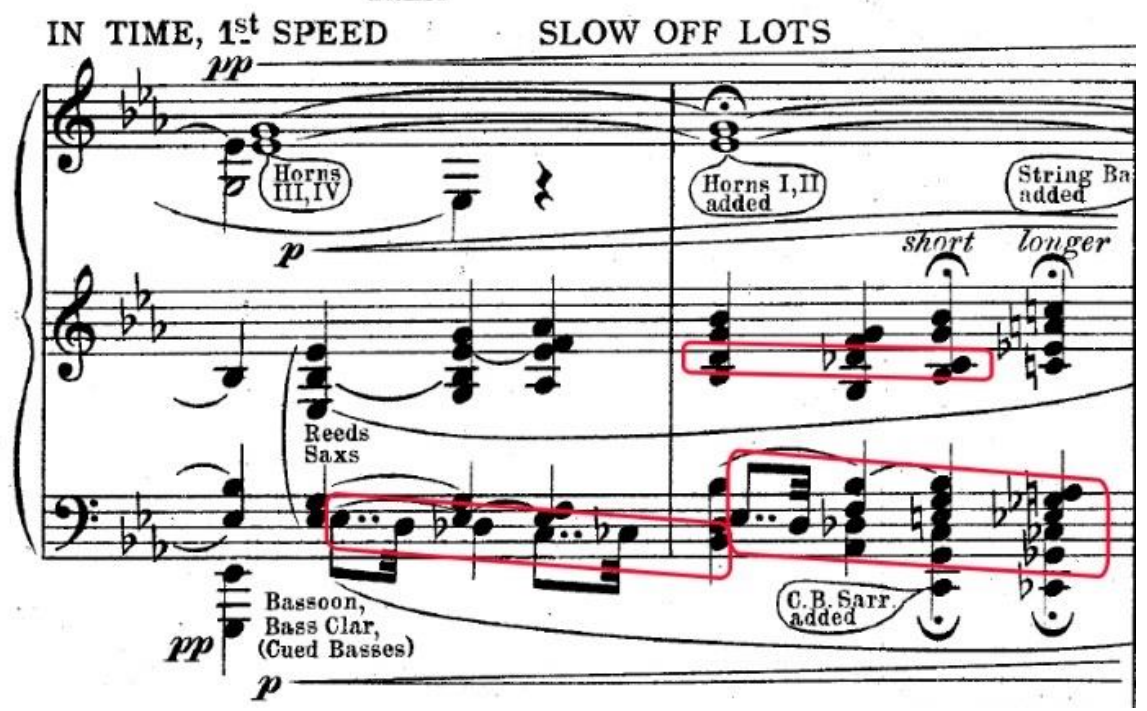

Figure 10. Colonial Song, mm. 66-67, condensed score. Descending chromaticism boxed (Grainger, 1921).

During the development section (measures 36-56), Grainger features several odd progressions resulting from voice leading. For example, measures 43-47 feature the following chords: $\mathrm{E} b 7 \mathrm{sus} / \mathrm{D} b \quad \mathrm{Cb} \quad \mathrm{G} b \quad \mathrm{~A} b m \mathrm{~Eb} / \mathrm{B}_{b} \quad \mathrm{~B}^{\circ} 9 \mathrm{Cm}$. This progression contains a plagal cadence in $\mathrm{G} b$, followed by a b6-b7-1 cadence in $\mathrm{B} b$ which ends on the cadential $\mathrm{I}^{6}{ }_{4}$ chord $\mathrm{E} b / \mathrm{B} b$. In the common practice period, this $\mathrm{E} b / \mathrm{B} b$ chord would typically move to $\mathrm{B} b$ (or $\mathrm{B} b 7$ ) and then resolve to $\mathrm{E} b$. Grainger instead moves to the more dissonant $\mathrm{B}^{\circ} 9$ chord, and then deceptively to $\mathrm{Cm}$. Grainger's use of untraditional progressions helps to enhance the development section of the piece by providing a more fluid harmony with room for various motives to be inserted, modified, and mixed together. At the end of the development section, Grainger introduces a new motive consisting of sliding thirds in the upper woodwinds and brass, as shown in Figure 11. This new motive lightens the mood of the piece and creates uncertainty about the exact moment the cadence will occur. Grainger also indicates a more fluid time signature and tempo to heighten this effect. 


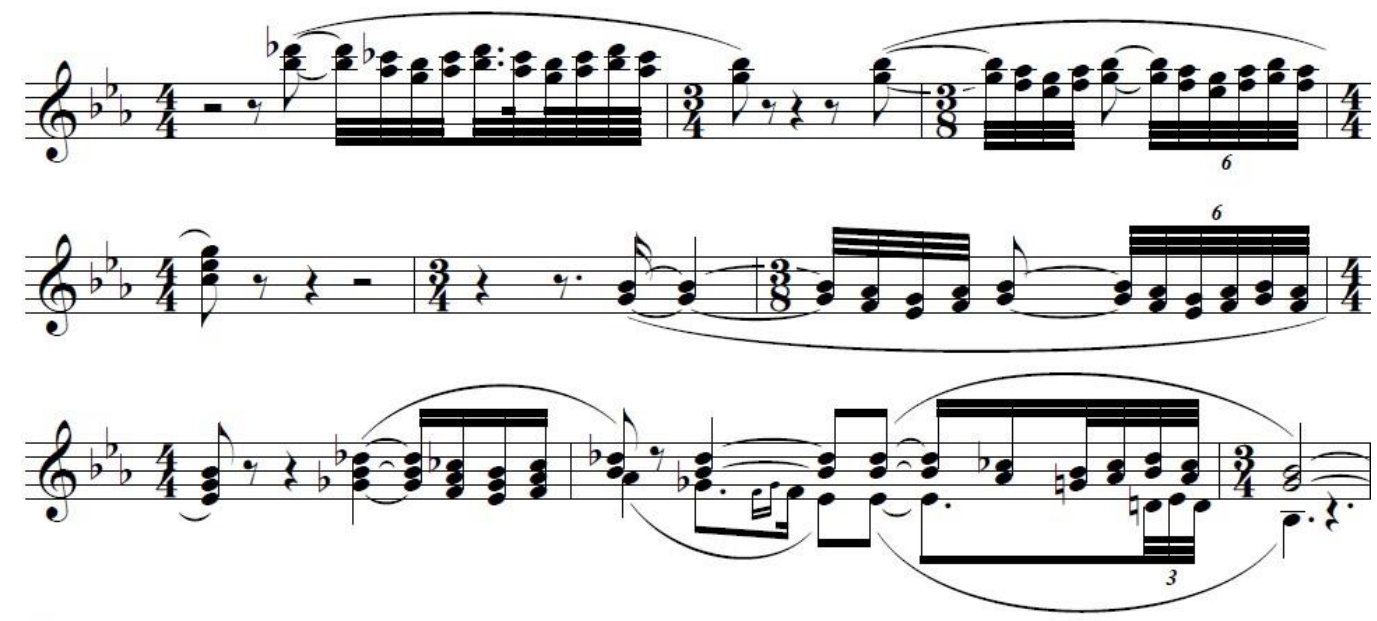

Figure 11. Colonial Song, mm. 44-52, only voices that move in parallel thirds (Grainger, 1921).

\section{Form and Melody}

The form of Colonial Song is fairly simple, consisting of an introduction, A section, B section, development, repetition of the A section, and conclusion (shown in Figure 12). The introduction material never truly repeats, although it is rhythmically and texturally similar to the piece's A section. The introduction consists of four 2-bar phrases with the form (aaba), which is a common form for sections of Grainger's pieces. The A section is also broken into 2-bar phrases, but these phrases take the form (aaaa), with each phrase having a slightly different melody but similar rhythms and cadences. The B section, like the introduction, is again broken into 2-bar phrases with the form ( $a a b a)$, although this form is more fluid and the $a$ phrases are not all exactly alike. The B section features heavier instrumentation on the second repetition, ending with a large crescendo that leads into the development.

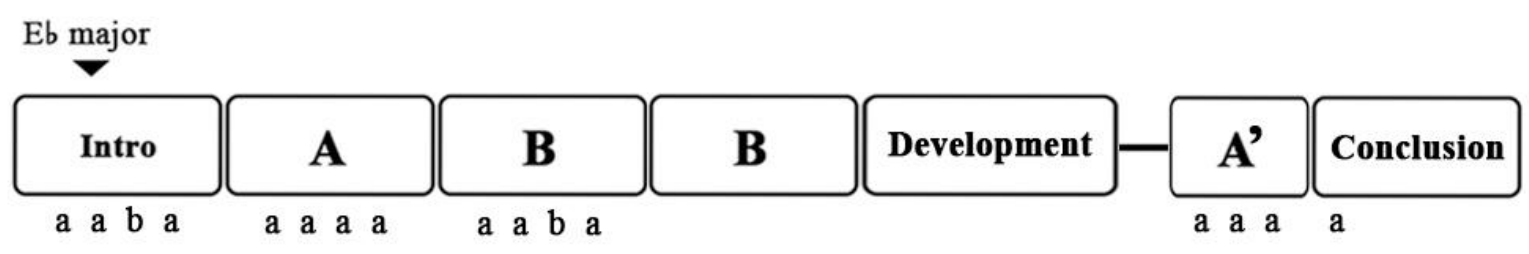

Figure 12. Form analysis of Colonial Song.

The development section combines several motives from the A and B sections and adds new ideas that help bring the piece to a climax. During this section, previous motives are thoroughly mixed to the point of being difficult to pick out individually. Grainger introduces a new motive in the woodwinds and upper brass, consisting of sliding parallel thirds. This motive is repeated 
several times, leading into what seems to be an extended half-cadence. The rest of the development section (measures 44-56) serves as a guide back to the A melody rather than a restatement of any particular motive. Grainger then ends the piece gradually, fading into a quiet $\mathrm{E} b$ major chord which is held for several measures while individual voices drop out in a staggered pattern.

The melodies Grainger uses in Colonial Song are simple yet expressive. As mentioned by R. Mark Rogers in his notes on the full score:

Most of Grainger's attempts at original composition... remain nearly unknown... However, when Grainger deliberately set out to compose in a folk-like vein... the resultant works are generally well-known and popular. (Grainger \& Rogers, 1997, p. 3)

Rogers considers Colonial Song to be perhaps the most well-crafted of Grainger's original works and attributes its popularity to the likeness of its melody to traditional British, Danish, and American folk songs. Grainger was a collector of folk music; he used a phonograph to record hundreds of folk songs from singers across England (Grainger, 1908), which he then used as inspiration for his compositions. Even though Colonial Song is an original work, the folk influence is clear from the piece's simple form and singable, diatonic melodies.
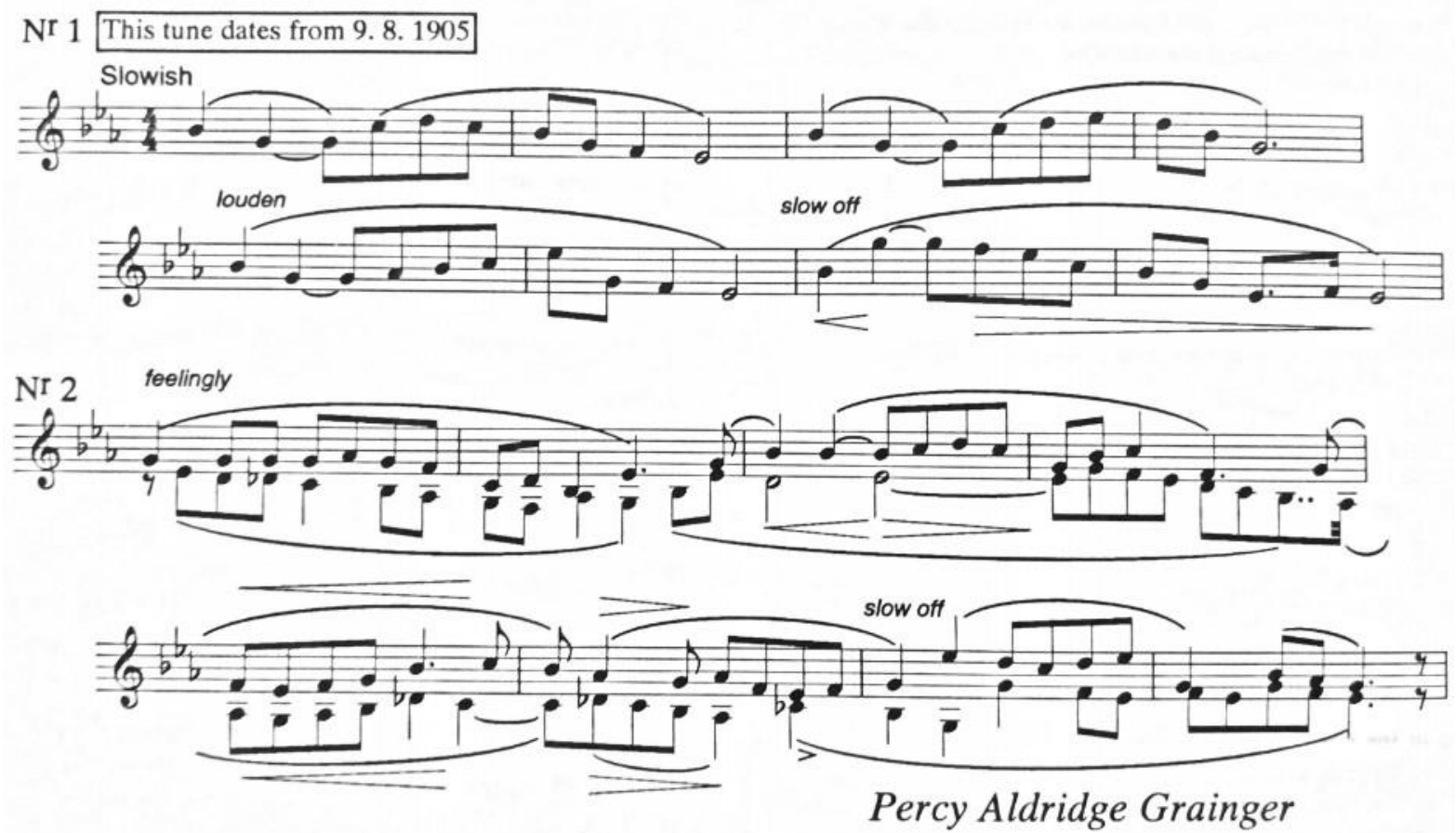

Figure 13. Colonial Song, A melody and B melody, respectively (Grainger \& Roberts, 1997, p. 2). 
The A melody of Colonial Song is very expressive and each phrase has a clear rise, peak, and fall. The final phrase's melody features a dramatic major sixth leap up to G5, which descends back down to $\mathrm{E} b 4$ and lands on a perfect authentic cadence. The B melody is more metric, and Grainger adds a fixed tempo and staccato accompaniment to reflect this shift. This new melody is vaguely connected to the A melody through the use of similar chords and cadences. However, while each two-bar phrase of the A melody has a very similar rhythm, the two-bar phrases of the B melody have the form (aaba).

\section{Texture}

21

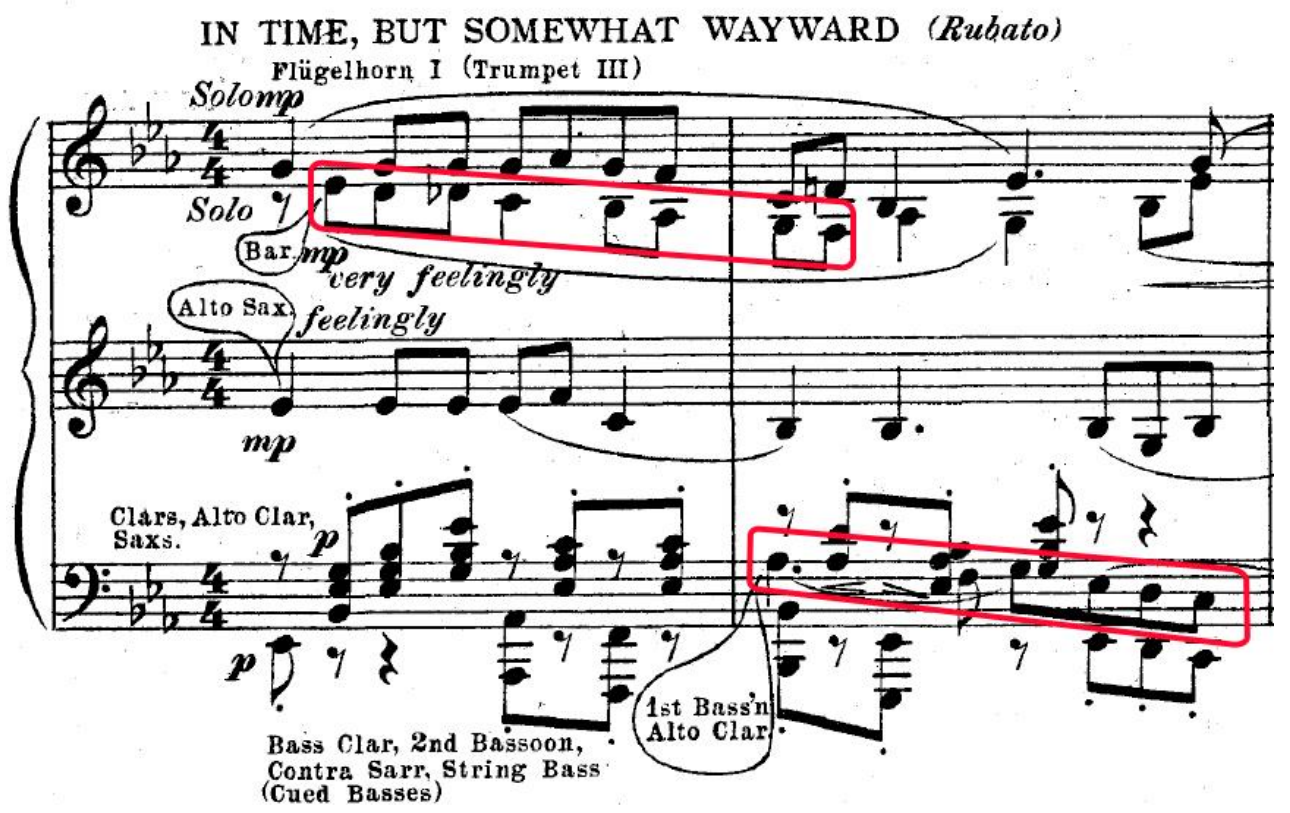

Figure 14. Colonial Song, mm. 21-22, condensed score. Descending countermelodies boxed (1921).

The texture of Colonial Song is mostly homophonic and follows a standard concept of melody and accompaniment for the first section of the piece, but then Grainger gradually introduces counterpoint and other melodic lines in several voices. For example, during the B section, the baritone plays a descending countermelody underneath the trumpet solo while several other instruments chime in with small melodic fragments (see Figure 14). During the development, there are two clear, contrasting ideas: the higher voices playing a smoother melodic line and a brass choir playing a sharp, piercing line that resembles the staccato accompaniment of the previous B section. Grainger builds various countermelodies as the piece 
progresses, often moving these lines in contrary motion to the main melody for emphasis. This slowly shifting texture seems to be a significant aspect of Grainger's compositional style.

\section{Rhythm}

Grainger establishes a free and flowing mood for the first 20 measures of Colonial Song. During the introduction and A section, Grainger uses directions like "flowingly," "with ample swells," and "slow off," making it clear that tempo and rhythms are not meant to be exact (1921). Cadential extensions during these sections are metered out with inserted beats and measures to give more instruction to the players. However, when the B section begins at measure 21, Grainger introduces staccato block chords underneath the flugelhorn and saxophone melody, and provides the instruction "[i]n time, but somewhat wayward" (1921, m. 21). At this point, the song speeds up and the tempo becomes more restricted, with the new staccato chords serving as a sort of metronome. These block chords return near the end of the piece in the second A section, where the A melody is played over the staccato block chords characteristic of the B section. Another notable rhythm that reoccurs in this piece is the double-dotted eighth and $32^{\text {nd }}$ note pattern (shown in Figure 10). This rhythm is repeated frequently with the intent to emphasize and complement the melody, as well as drive the melody forward.

\section{Conclusions}

Children's March and Colonial Song are not representative of the complete oeuvre of Percy Grainger, but they share important elements which provide insight into Grainger's general compositional style. Grainger establishes tertian harmony as the standard in both pieces and then introduces other factors that interrupt this standard to provide momentary tension. Most notably, Grainger builds chords around descending chromatic lines, creates tension by increasing the density of notes, and exploits the properties of tritones and seventh chords to create descending chains that slowly release tension. Descending chromaticism is not unique to Grainger's works, but the particular ways in which he uses chromatic lines are. Both pieces also have a logical yet somewhat free-flowing form, and this seems to be true of much of Grainger's music. The forms of Grainger's songs allow for simple diatonic melodies to be established, repeated, developed, and reharmonized with various techniques.

The texture of Grainger's compositions tends to lie somewhere between homophony and polyphony, as various countermelodies periodically complement the melody and accompaniment. This stylistic choice makes sense for Grainger, as many of his pieces were 
either inspired by or directly taken from various folk tunes which lend themselves well to homophony (Freeman, 2012). Children's March and Colonial Song are both original works, but the folk influence is clear due to Grainger's use of diatonic melodies and simple textures. Grainger's common rhythmic choices include the double-dotted eighth and $32^{\text {nd }}$ note pattern, staccato block chords, and the Scotch snap. The first two of these serve as rhythmic driving forces and are appropriate for emulating or accompanying a folk song with a constant tempo, whereas the Scotch snap is a common rhythm in folk songs from the geographic region where Grainger collected and recorded folk music (Grainger, 1908; Johnson, 2001). Many of Grainger's stylistic choices were more traditional than his early twentieth-century contemporaries who were exploring atonality, polytonality, primitivism, pandiatonicism, and other new compositional concepts. However, as evidenced by the harmonic analysis above, he still takes some influence from more modern styles. It is this combination of simple traditional music and occasionally complex harmony that sets Grainger apart from his contemporaries and makes his compositional style easily identifiable.

\section{Acknowledgements}

I would like to express my sincere gratitude to my faculty mentor, Dr. Rich Pellegrin, for his support and feedback throughout the process of research, analysis, and writing this paper. Additionally, I would like to thank the University of Florida and the Center for Undergraduate Research for providing me with this opportunity to pursue and publish research in a subject area for which I have a great passion.

\section{References}

Bakan, M. B. (2012). 'Not the Same, but Just as Nice': Traditions and Transformations in Irish Music. In World Music: Traditions and Transformations (2nd ed., p. 165). Boston, MA: McGraw Hill.

Freeman, G. (2012). 'Into a cocked-hat': The folk song arrangements of Percy Grainger, Cecil Sharp and Benjamin Britten. Grainger Studies: An Interdisciplinary Journal, 1(2), 33-54. Retrieved July 1, 2021, from http://hdl.handle.net/11343/118256

Grainger, P. A. (1908). Collecting with the Phonograph. Journal of the Folk-Song Society, 3(12), 147162. Retrieved July 1, 2021, from http://www.jstor.org/stable/4433924

Grainger, P. A. (1919). Children's March: “Over the hills and far away” [Condensed score]. G. Schirmer, Inc., New York.

Grainger, P. A. (1921). Colonial Song [Condensed score]. Carl Fischer, New York.

Grainger, P. A. (1995). Children's March: “Over the hills and far away” (R. M. Rogers, Ed.) [Musical score]. Southern Music Company. (Original work published 1919) 
Grainger, P. A. (1997). Colonial Song (R. M. Rogers, Ed.) [Musical score]. Southern Music Company. (Original work published 1921)

Johnson, D. (2001). Scotch snap. Grove Music Online. https://doi.org/10.1093/gmo/9781561592630.article.25244

Temperley, N., \& Temperley, D. (2011). Music-Language Correlations and the "Scotch Snap." Music Perception, 29(1), 51-63. https://doi.org/10.1525/mp.2011.29.1.51 